\title{
Magnesium isotope behaviors during authigenic carbonate precipitation driven by anaerobic methane oxidation
}

\author{
ZEKUN MENG ${ }^{1}$, DONG FENG ${ }^{2}$, XIN-YUAN \\ ZHENG $^{3}$, KANGJUN HUANG $^{1}$
}

${ }^{1}$ State Key Laboratory of Continental Dynamics,Department of Geology,Northwest University, Xi'an 710069, China

${ }^{2}$ Shanghai Engineering Research Center of Hadal Science and Technology, College of Marine Sciences, Shanghai Ocean University, Shanghai 201306, China

${ }^{3}$ Department of Earth and Environmental Sciences, University of Minnesota-Twin Cities, Minneapolis MN 55455, USA

Formation of authigenic carbonate during anaerobic oxidation of methane (AOM) in cold-seep environments has been invoked as a critical but previously neglected process in regulating the carbon cycle over Earth's history. Because Mg can be incorporated into crystal lattices of authigenic carbonates, this process, in principle, can play an important role in the global biogeochemical cycle of $\mathrm{Mg}$. However, its contribution has not been quantified.

To estimate the influence of AOM-induced authigenic carbonate formation on the global $\mathrm{Mg}$ cycle, we investigate $\mathrm{Mg}$ isotope systematics in cold-seep sediments and pore fluids collected from Shenhu area in the South China Sea. $\delta^{26} \mathrm{Mg}$ values of pore fluids systematically increase with depths from $-0.82 \%$ at 1 meter below the seafloor (mbsf) to $0.62 \%$ at $8 \mathrm{mbsf}$. In contrast, $\delta^{26} \mathrm{Mg}$ values of the co-existing AOM-induced authigenic carbonates are lower, and broadly decrease with depths from $-1.15 \%$ to $-1.50 \%$. The apparent $\mathrm{Mg}$ isotope fractionation between carbonates and pore fluids ( $\alpha_{\text {car-sol }}$ ) ranges from 0.99919 to 0.99974 . The magnitude of this fractionation appears to be considerably smaller than that associated with formation of abiotic and biotic $\mathrm{Mg}$-bearing carbonates in non-AOM areas in the global ocean $\left(\alpha_{\text {car-sol }}=\right.$ 0.99517 to 0.99964 ) (Saenger and Wang, 2014), possibly reflecting high precipitation rates of carbonate formation induced by AOM at cold seeps. These results provide new constraints on the $\mathrm{Mg}$ flux associated with AOM-induced authigenic carbonates and its significance in the $\mathrm{Mg}$ cycle in the global ocean. 